УДК 65.012.2

\title{
РАЗРАБОТКА ТЕХНОЛОГИЧЕСКОЙ ДОРОЖНОЙ КАРТЫ ПРОЦЕССА УПРАВЛЕНИЯ КОМПЛЕКСНОЙ БЕЗОПАСНОСТЬЮ ОБЪЕКТОВ, ПОДЛЕЖАЩИХ ОБЯЗАТЕЛЬНОЙ ГОСУДАРСТВЕННОЙ ОХРАНЕ
}

\author{
А. А. Рогожин ${ }^{\star}$, Б. О. Баторов ${ }^{\star *}$, В. А. Дурденко ${ }^{\star \star *}$ \\ ${ }^{*}$ Краснодарский университет МВД России \\ **Академия управления МВД России

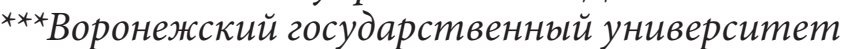

Поступила в редакцию 02.02.2018 г.

\begin{abstract}
Аннотация. В статье разработана технологическая дорожная карта процесса управления комплексной безопасностью объектов, подлежащих обязательной государственной охране. Ключевые слова: классификация, прогнозирование, экспертиза, интегрированная система безопасности, нейронная сеть, метод, персептрон.

Annotation. In article the method of classification and prediction of the structures of the integrated security systems based on modeling of pre-trained perceptron is realized.

Keywords: classification, prediction, assessment, the integrated security system, neural network, method, perceptron.
\end{abstract}

\section{ВВЕДЕНИЕ}

Обеспечение комплексной безопасности объектов, подлежащих обязательной государственной охране, неразрывно связано с внедрением современных интегрированных систем безопасности (ИСБ) [1, 2], объединяющих подсистемы охранной и тревожной сигнализации (СОТС), пожарной сигнализации (СПС), охранного телевидения (СОТ), контроля и управления доступом (СКУД), управления жизнеобеспечением (СУЖ), а также выполнением мероприятий по инженерно-технической укрепленности (ИТУ) конструктивных элементов объекта и по созданию дежурно-диспетчерской службы (ДДС). Для совершенствования системы управления безопасностью объектов, подлежащих обязательной государственной охране, с точки зрения повышения эффектив2018 ности и надежности ее функционирования, необходимо использование современной теории управления и принятия решений.

В настоящее время теория управления и принятия решений направлена на поиск методов и инструментов, позволяющих повысить эффективность и надежность функционирования социальных и экономических систем [3]. Например, в статье [4] проведен сравнительный анализ методов принятия управленческих решений, среди которых метод Дельфи, SWOT-анализ, метод мозгового штурма, метод сценариев, метод дерева целей, метод дорожного картирования. Одним из наиболее прогрессивно развивающихся методов является «Дорожная карта», который основывается на дедуктивном разложении процесса достижения цели на этапы (шаги), этот процесс называется дорожным картированием. В общем виде, дорожное картирование служит информационной основой поддержки процесса управления и принятия решений, а в частности, служит для разработки этапов развития 


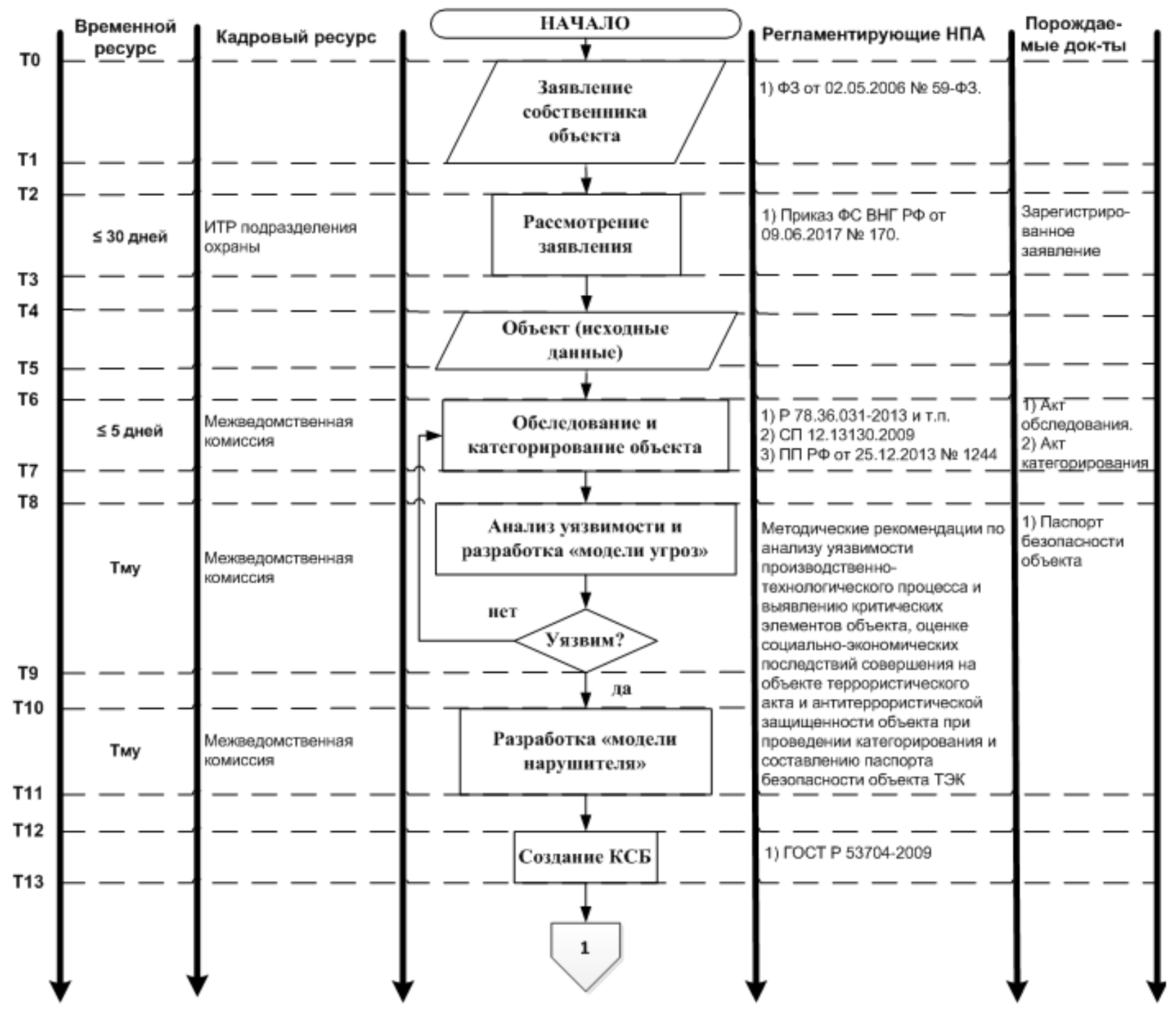

Рис. 1. ТДК процесса управления комплексной безопасностью объектов, подлежащих обязательной государственной охране (начало)

объекта или процесса и определения времени принятия управленческих решений, а также для логического обоснования причинно-следственных связей между различными этапами «Дорожной карты». В работе [5] показано многообразие подходов к построению дорожных карт. В статье [6] представлены результаты исследования, посвященного инструменту «Технологическая дорожная карта» (ТДК).

Для повышения эффективности и надежности функционирования системы управления комплексной безопасностью объектов, подлежащих обязательной государственной охране, весьма актуальным является решение научной задачи разработки ТДК процесса управления комплексной безопасностью вышеуказанных объектов.

В этой связи целью настоящей статьи является разработка ТДК процесса управления комплексной безопасностью объектов, подлежащих обязательной государственной охране.

\section{ОСНОВНАЯ ЧАСТЬ}

Перечень объектов, подлежащих обязательной государственной охране, и на которые соответственно не распространяется частная охранная деятельность, утвержден постановлением Правительства Российской Федерации [7]. 


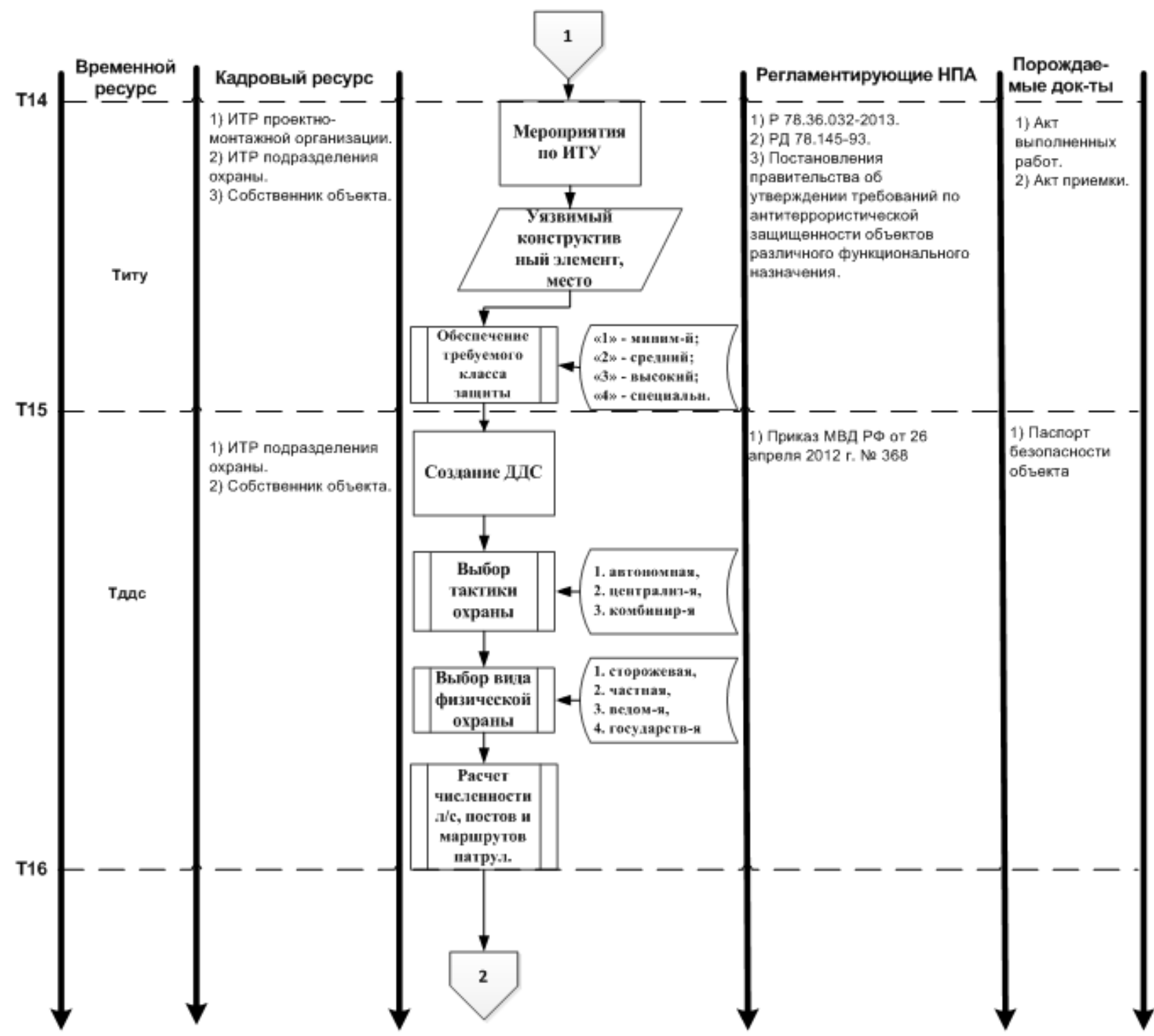

Рис. 1. ТДК процесса управления комплексной безопасностью объектов, подлежащих обязательной государственной охране (продолжение 1)

Необходимо отметить, что в настоящее время безопасность объектов, подлежащих обязательной государственной охране, как правило, осуществляют подразделения вневедомственной охраны Росгвардии, ФГУП «Охрана» Росгвардии, ведомственной охраны.

Предпосылками разработки ТДК процесса управления комплексной безопасностью объектов, подлежащих обязательной государственной охране, будем считать публикации $[8,9]$, методологической основой - теорию управления и принятия решений.

Необходимость проводимого исследования обусловлена повышением эффективности и надежности системы управления комплексной безопасностью объектов, подлежащих обязательной государственной охране, и направлена на:

1. Обеспечение необходимого уровня защищенности объектов, подлежащих обязательной государственной охране, от проектных угроз.

2. Предупреждение, обнаружение, пресечение угроз в отношении объектов, подлежащих обязательной государственной охране.

3. Минимизацию или недопущение возможного ущерба физическим и юридическим лицам, обществу, государству, экологии за счет оперативной ликвидации последствий от реализованных угроз на объектах, подлежащих обязательной государственной охране. 


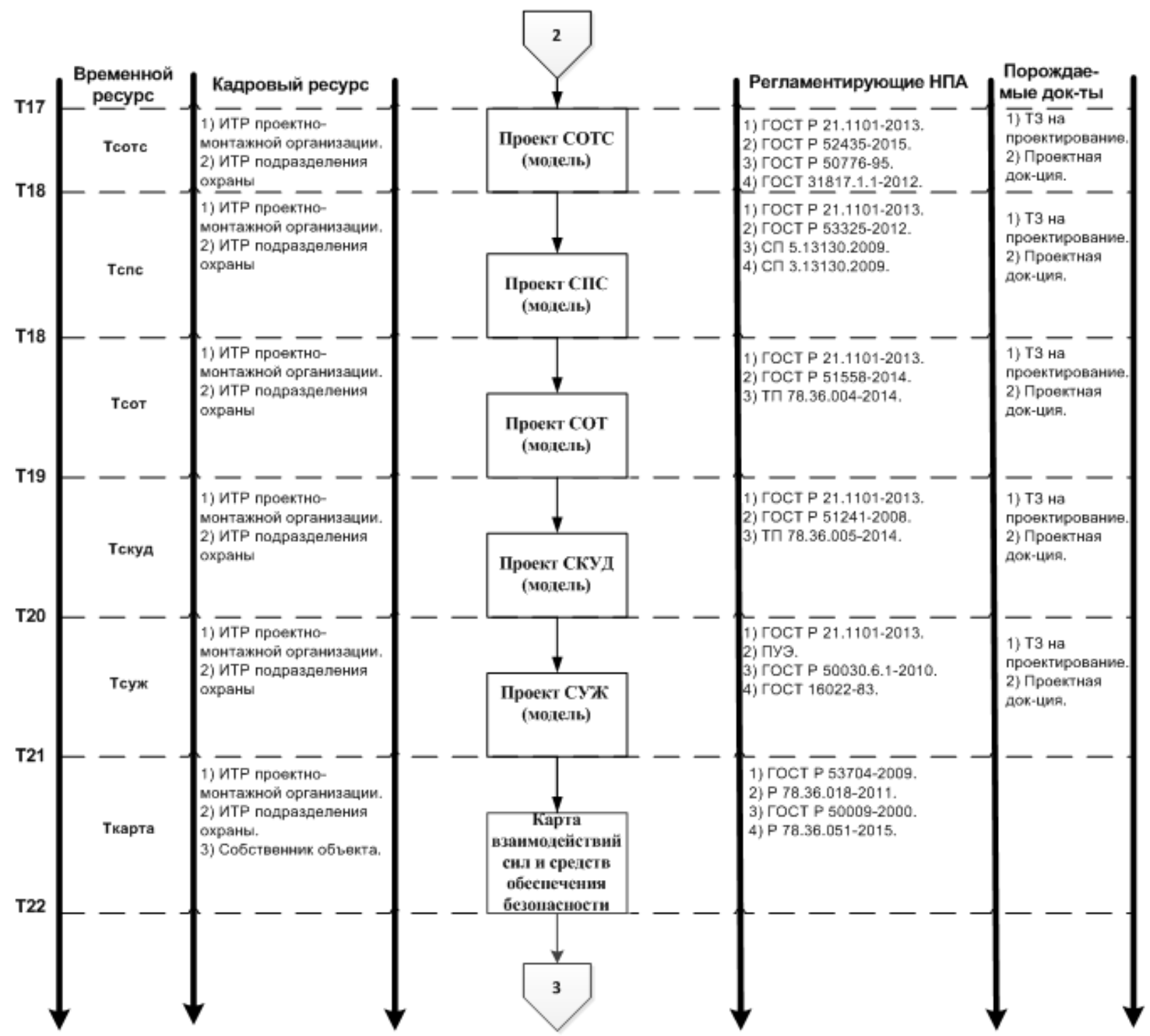

Рис. 1. ТДК процесса управления комплексной безопасностью объектов, подлежащих обязательной государственной охране (продолжение 2)

Предложенная ТДК построена с использованием графического аппарата блок-схем алгоритмов и включает в себя: все этапы управления комплексной безопасностью объектов, подлежащих обязательной государственной охране, необходимые условия реализации отдельных этапов, причинно-следственные связи между различными подпроцессами и этапами в виде стрелок, привлекаемые на каждом этапе временные и кадровые ресурсы, а также регламентирующие каждый этап нормативные правовые акты и, соответственно, порождаемые организационно-распорядительные и иные документы.

\section{ОБСУЖДЕНИЕ РЕЗУЛЬТАТОВ}

По мнению авторов, разработка ТДК процесса управления комплексной безопасностью объектов, подлежащих обязательной государственной охране, характеризуется и практической, и теоретической значимостью как для собственника объекта, так и для исполнителей соответствующих работ по обеспечению комплексной безопасности объекта.

ТДК позволит заказчику обеспечения комплексной безопасности (собственнику) объекта, подлежащего обязательной государственной охране, иметь наглядное представление: 


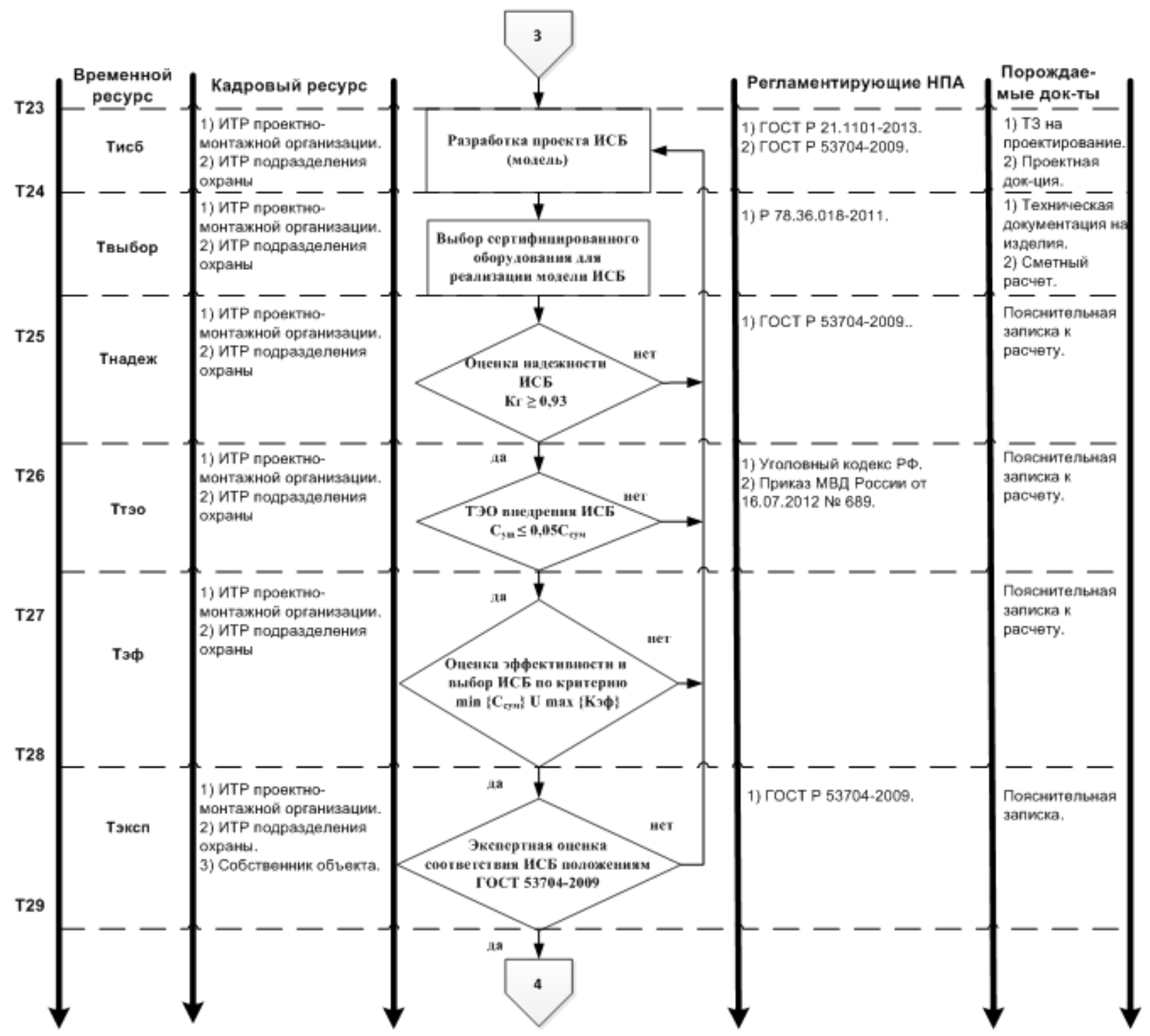

Рис. 1. ТДК процесса управления комплексной безопасностью объектов, подлежащих обязательной государственной охране (продолжение 3)

- об уязвимости своего объекта к криминальным и террористическим угрозам и принимать соответствующие управленческие решения об инвестировании процесса обеспечения комплексной безопасности уязвимых мест на определенный период времени;

- об уровне защищенности своего объекта на период времени для рационального ресурсного обеспечения внедряемой ИСБ, т. е. комплектования ЗИП;

- об экономической эффективности проводимых мероприятий в заданный момент времени и принимать соответствующие управленческие решения;
- о надежности и эффективности ИСБ своего объекта в заданный момент времени и принимать соответствующие управленческие решения по их повышению.

ТДК позволит исполнителям работ (проектно-монтажной организации, подразделению охраны) по обеспечению комплексной безопасности объекта, подлежащего обязательной государственной охране:

- иметь мощный маркетинговый инструмент для внедрения своей технологии обеспечения комплексной безопасности в деятельность объекта; 


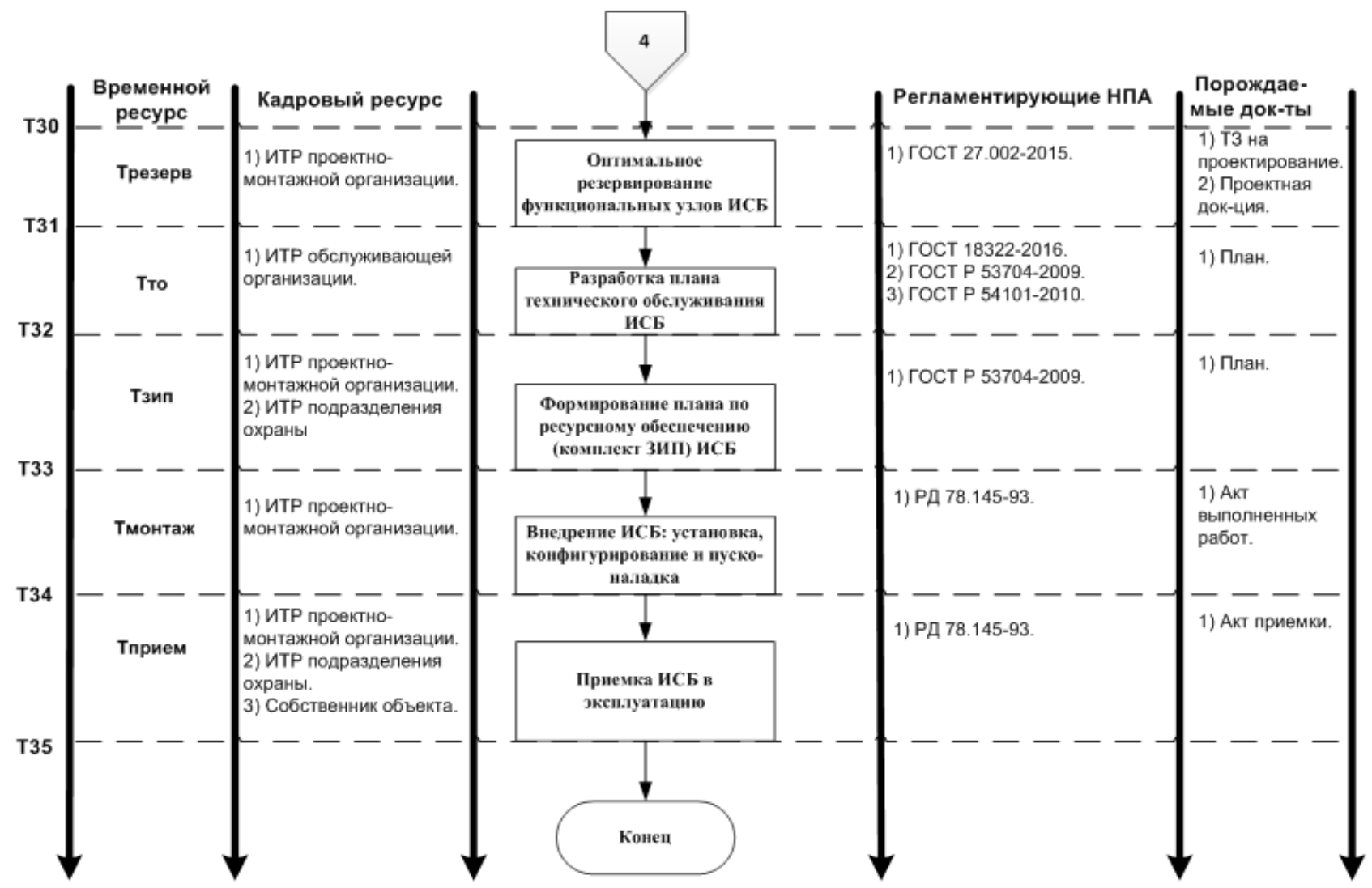

Рис. 1. ТДК процесса управления комплексной безопасностью объектов, подлежащих обязательной государственной охране (конеи)

- применять ТДК на объектах, как типовое решение обеспечения комплексной их безопасности;

- наглядно демонстрировать заказчику качество внедряемой технологии обеспечения комплексной безопасности в заданный момент времени и, одновременно, производить количественную оценку надежности и эффективности ИСБ в целях удовлетворения потребностей заказчика;

- оперативно разрабатывать комплекс мероприятий по техническому обслуживанию ИСБ.

\section{ЗАКЛЮЧЕНИЕ}

Предложенная ТДК направлена на совершенствование системы управления безопасностью объектов, подлежащих обязательной государственной охране, с точки зрения повышения эффективности и надежности ее функционирования. ТДК может оказать существенную поддержку лицу, принимаю- щему решения, на всех этапах управления комплексной безопасностью объектов за счет наглядного представления проводимых мероприятий и затрачиваемых ресурсов.

Для каждого конкретного уникального по своей архитектуре и функциональным особенностям объекта может быть разработана специализированная ТДК процесса управления комплексной безопасностью, при этом основой может послужить дорожная карта, предложенная в настоящей статье.

\section{СПИСОК ЛИТЕРАТУРЫ}

1. Рогожин, А. А. Основы построения интегрированных систем безопасности : учеб. пособие / А. А. Рогожин. - Воронеж : Воронежский институт МВД России, 2012. - 74 с.

2. Рогожин, А. А. Разработка классификации и архитектуры построения интегрированных систем безопасности / А. А. Рогожин, В. А. Дурденко // Вестник Воронеж. гос. ун-та. 
Разработка технологической дорожной карты прочесса управления комплексной безопасностью ...

Сер. Системный анализ и информационные технологии. - 2013. - № 1. - С. 61-70.

3. Паспорт научной специальности 05.13.10 Управление в социальных и экономических системах : Паспорта научных специальностей ВАК. - Режим доступа : http://vak.ed.gov. ru/316 (дата обращения 18.01.2018).

4. Черепанов, M. А. Дорожная карта как инструмент управления развитием организации / М. А. Черепанов // Вопросы управления. - 2014. - № 5 (30). - Режим доступа : http:/vestnik.uapa.ru/ ru/issue/2014/05/05/ (дата обращения 18.01.2018).

5. Лидин, К. Л. Многообразие построения дорожных карт / К. Л. Лидин. - Режим доступа : http://www.virtass.ru/ IO/14_5.doc (дата обращения 18.01.2018).

6. Матич, Л. Ю. Технологические дорожные карты: использование в инновационной деятельности крупных компаний / Л. Ю. Матич // Российский журнал менеджмента. 2017. - Т. 15. - № 3. - С. 327-356.

7. Вопросы частной детективной (сыскной) и частной охранной деятельности : по-

Рогожин Александр Александрович - преподаватель кафедры информационной безопасности Краснодарского университета МВД России.

Тел.: (961) 523-69-64

E-mail: raa_tsbs@list.ru

Баторов Батор Октябрьевич - адъюнкт кафедры информационных технологий Академии управления МВД России.

Тел.: (983) 435-31-33

E-mail: 03bator@rambler.ru

Дурденко Владимир Андреевич - д-р техн. наук, профессор кафедры информационных технологий управления, Воронежский государственный университет.

Тел.: (473) 228-11-60

E-mail: dva_viis@mail.ru становление Правительства Российской Федерации от 14 августа 1992 года № 587. - Режим доступа: http://docs.cntd.ru/document/9005131 (дата обращения 18.01.2018).

8. Рогожин, А. А. Инновационный подход к моделированию процесса обеспечения комплексной безопасности объектов на основе дорожного картирования / А. А. Рогожин, В. А. Дурденко // Общественная безопасность, законность и правопорядок в III тысячелетии : материалы международной научно-практической конференции. - Воронеж: Воронежский институт МВД России, 2012. - C. 75-80.

9. Рогожин, А. А. Алгоритм обеспечения комплексной безопасности объектов / А. А. Рогожин // Информатизация и информационная безопасность правоохранительных органов : сборник трудов XXV Всероссийской научно-практической конференции. - Москва : Академия управления МВД России, 2017. - С. 155-160.

Rogozhin Alexander A. - Lecturer, Department of information security, Krasnodar university of the Ministry of the Interior of Russia.

Tel.: (961) 523-69-64

E-mail: raa_tsbs@list.ru

Batorov Bator O. - postgraduate student, Department of information technology, Academy of management of the Ministry of the Interior of Russia.

Tel.: (983) 435-31-33

E-mail: 03bator@rambler.ru

Durdenko Vladimir A. - Doctor of Technical Sciences, Professor, Department of information technology management, Voronezh State University.

Tel.: (473) 228-11-60

E-mail: dva_viis@mail.ru 